\title{
Effect of liquid column on process stability and weld formation under ultra-high power fiber laser- arc hybrid welding of thick plates
}

Yan Li

Shaoning Geng

Siyuan Gu

Dehua Huang

Yilin Wang

Gaoyang Mi

Ping Jiang ( $\sim$ jiangping@hust.edu.cn )

Huazhong University of Science \& Technology

\section{Research Article}

Keywords: ultra-high power laser-arc hybrid welding, process stability, liquid column, keyhole entrance, weld formation

Posted Date: February 24th, 2022

DOI: https://doi.org/10.21203/rs.3.rs-1375910/v1

License: (9) This work is licensed under a Creative Commons Attribution 4.0 International License. Read Full License 


\section{Abstract}

Liquid column was a common problem in ultra-high power fiber laser-arc hybrid welding (UHLAHW) process, which has an adverse effect on the welding stability and weld formation. Hence, the influence of welding parameters on the behavior of liquid column were investigated systematically, including laser arc recombination process, laser power and welding speed. As a result, the violent rising liquid column under laser was suppressed markedly after arc addition. However, it was hardly to restrain liquid column upturn when laser power was extremely high, because the huge recoil pressure and shear force between metal vapor/plasma and molten pool could increase the upward momentum of melt. Besides, the height of liquid column and volume of spatters were directly influenced by welding speed, due to the welding line energy could significantly influence the flow of melt on the front of keyhole. By optimizing the welding process, the liquid column could be controlled and thus improved the stability. Finally, a sound weld bead with qualified weld formation and $15.82 \mathrm{~mm}$ penetration was produced when the laser power was $21 \mathrm{~kW}$ and welding speed was $1.2 \mathrm{~m} / \mathrm{min}$ under UHLAHW process. This work provides technical guidance for achieving stable welding process and qualified weld formation for thick plates.

\section{Introduction}

Thick-section structure of more than $15 \mathrm{~mm}$ is critical to the manufacturing process in many industries including marine equipment, rail transit, nuclear power and other engineering fields [1]. Laser-arc hybrid welding (LAHW) can combine the advantages of laser and arc heat sources, including high energy density, fast welding speed, small heat affected zone and strong gap tolerance, provides an effective method for joining [2]. However, the hybrid welding is mainly focused on the kilowatt-level research at present, and thus suppresses the depth penetration. With the successful development of ultra-high power fiber lasers (powers above $10 \mathrm{~kW}$ ), it is possible to realize depth penetration of thick plate with singlepass [3]. Therefore, ultra-high power fiber laser-arc hybrid welding is becoming a research hotspot in thick plate joining. But the ultra high energy density of laser beam will produce huge recoil pressure and shear force between metal vapor/plasma [4], leading to liquid column rise sharply, arc jump violently, and thus have a detrimental effect on welding stability.

Comparing with conventional LAHW (laser power below $10 \mathrm{~kW}$ ), the advantages of UHLAHW process were as following: ultra-high energy density, penetration and welding productivity [5]. However, relevant literatures demonstrated that many defects were easier to be formed under ultra-high power laser (UHLW) process, such as undercut, liquid column, spatter and crack, etc [6]. Liquid column would rise sharply, and lead to large amounts spatters formation, which were an remarkable feature of UHLAHW. The spatter was formed when the momentum of melt at the rear of liquid column was high enough to surmount the surface tension [7]. Therefore, seeking a suitable method to suppress the violent rising of liquid column was the key to reduce spatter formation. Here, the strong rising melt was attributed to the viscous drag between vapor plume and molten metal [8]. Therefore, reducing the concentration and suppressing the rising speed of metal vapor were effective methods to inhibit the formation of liquid column. Adding a larger side shielding gas flow could blow away the plasma plume under kilowatt-level laser welding [9], 
however, it has little effect on high concentration plasma under UHLW [10]. Reducing the ambient pressure was also a method to suppress plasma plume and improve the stability of welding process [6], but proposed a higher requirement on the equipment. The velocity of metal vapor was also intimately related with keyhole dynamic evolution. Relevant studies pointed that the liquid column was notably influenced by the keyhole entrance, which could stretch gradually as the reduce of keyhole mouth size [11]. Therefore, it is urgent to explore suitable methods to enlarge keyhole entrance.

The material would violently evaporate when the laser beam irradiate on the surface. The vaporization would generate recoil pressure, and then creating the keyhole [12]. The keyhole behavior played a vital role in the welding stability, which were determined by the heat transfer and melt metal flow [13]. However, related reports indicated that the unstable and violent oscillations were the notable features of keyhole behaviors [14]. Ai et al. [15] found that the constriction would be formed and moved to the keyhole inlet under the forces, including recoil pressure, surface tension and hydrostatic pressure, leading to a narrow keyhole entrance. The keyhole entrance shape was obviously influenced by the changed forces on the surrounded melt metal. Schmidt et al. [16] pointed that the direction of shielding gas flow to the rear keyhole wall would affect the keyhole stability during high welding speed condition, because the shielding gas could effectively balance the internal pressure of keyhole. However, the pores would be generated when adding a large amount of shielding gas. Liu et al. [17] found that the keyhole entrance was influenced by welding current and welding speed, which enlarged with the increasing welding current and decreasing welding speed to some extent. Kim et al. [18] studied the influence of ambient pressure on keyhole shapes and found that the keyhole of zinc-coated steel would be noticeably enlarged under reduced ambient pressures. Wang et al. [19] observed the keyhole bottom entrance and found that the unstable phenomenon was more obvious with the increase of laser power. Wu et al. [20] analysed the reason of the keyhole formation under plasma arc welding, found that the arc pressure driven weld pool deformation played a dominant role on keyhole entrance. Wang et al. [21] found that both the droplet transfer and laser power would influence the keyhole states under laser-MAG hybrid welding process (the laser power changed from $2 \mathrm{~kW}$ to $5 \mathrm{~kW}$ ). However, the research on the influence of the laser beam and arc on the keyhole behavior was mainly focused on the kilowatt laser. The interaction between laser and arc became more complicated when the laser power exceeded $10 \mathrm{~kW}$. Therefore, how to enlarge the keyhole and improve the welding stability during UHLAHW process were still worth to be further explored.

In order to explore the influence of welding parameters on the liquid column, spatter formation and joint morphology under UHLAHW. Mild steel plates $20 \mathrm{~mm}$ thick were welded and the main parameters were investigated, including laser arc recombination process, laser power, and welding speed. The interaction between liquid column and keyhole entrance were discussed, and the stable welding process and qualified weld formation was presented through optimizing the parameters.

\section{Equipment And Materials}

The base metal (BM, Q235 mild steel) with $20 \mathrm{~mm}$ thickness and filling wire (ER50-6) with a diameter of $1.2 \mathrm{~mm}$ were used in this study. And their chemical compositions were listed in Table 1. 
Table 1

Chemical compositions of BM and welding wire (mass fraction: \%).

\begin{tabular}{|llllllll|}
\hline Materials & $\mathbf{C}$ & $\mathbf{S i}$ & $\mathbf{M n}$ & $\mathbf{P}$ & $\mathbf{S}$ & Others & $\mathrm{Fe}$ \\
\hline Q235 & $\leq 0.2$ & $\leq 0.35$ & $\leq 1.4$ & $\leq 0.045$ & $\leq 0.045$ & - & Bal. \\
\hline ER50-6 & $0.06-0.15$ & $1.15-1.8$ & $1.4-1.85$ & $\leq 0.025$ & $\leq 0.035$ & $\leq 0.5$ & Bal. \\
\hline
\end{tabular}

UHLAHW system was utilized consisting of 30 kW IPG YLS-30000 CW fiber laser and KEMPPI welding machine. Furthermore, the output laser power was up to $30 \mathrm{~kW}$ with a wavelength of $1070 \mathrm{~nm}$, a transmission diameter of $0.3 \mathrm{~mm}$ and a focus spot of $1.2 \mathrm{~mm}$. Specifically, the laser beam was deviated from vertical direction by $10^{\circ}$ to prevent back reflections in the optical system [22]. The angle between filler wire axis and laser beam was set as $30^{\circ}$. Concrete experimental devices and schematic of the welding processes were displayed in Fig. 1. The shielding gas emitting out from arc torch was a mixture of argon and carbon dioxide $\left(82 \% \mathrm{Ar}+18 \% \mathrm{CO}_{2}\right)$ at $25 \mathrm{~L} /$ min while side-blowing nozzle was pure argon at $35 \mathrm{~L} / \mathrm{min}$. Other welding parameters were supplemented in Table 2.

The VRI V611 high speed camera (HSC) with a sampling rate of $5000 \mathrm{fps}$ was used to record the arc shape, droplet transfer, molten pool flow, liquid column and spatters. Finally, optical microscope was adopted to observe appearance and transverse section of welded joints.

Table 2

The main welding parameters.

\begin{tabular}{|ll|}
\hline Welding parameters & \\
\hline Laser power $\mathrm{P}(\mathrm{kW})$ & $9-27$ \\
\hline MAG current I $(\mathrm{A})$ & 163 \\
\hline Heat source arrangements & MAG-Laser \\
\hline Welding speed $v_{\mathrm{m}}(\mathrm{m} / \mathrm{min})$ & $0.9-1.5$ \\
\hline Defocused distance $\Delta f(\mathrm{~mm})$ & -2 \\
\hline Distance between laser and arc $D_{L A}(\mathrm{~mm})$ & 3 \\
\hline
\end{tabular}

\section{Results And Discussion}

\subsection{Effect of UHLW and MAG interaction on liquid column and weld formation}

There existed a strong synergetic effect between laser and arc when the level of laser power below $10 \mathrm{~kW}$, which could improve the stability of the welding process [23]. However, when laser power above $10 \mathrm{~kW}$, 
ultra-high energy intensity $\left(10^{6} \mathrm{~W} / \mathrm{cm}^{2} \sim 10^{7} \mathrm{~W} / \mathrm{cm}^{2}\right)$ could cause the surface of the material violently evaporate [4]. Thus, the interaction between the violently erupting metal vapor and the arc was more complicated. In order to further explore the effect of interaction between laser and arc on liquid column, spatters and arc characteristic, the solo-UHLW, solo-MAG welding, and UHLAHW were carried out respectively.

The welding stability would be markedly reduced when ultra-high energy intensity of laser beam acted directly on the workpiece. As shown in Fig. 2, the shape of liquid column changed continuously during the welding process. At the time instant of $\mathrm{t}_{0} \mathrm{~ms}$, the keyhole was generated by laser irradiation. The molten metal was taken out of the molten pool and formed an inclined liquid column along the welding direction at $t_{0}+2.4 \mathrm{~ms}$. This phenomenon could be attributed to the strong impact of metal vapor on molten pool wall, including the frictional force and shear force. The shear force was generated by the friction effect between high-speed jet of metal vapor/plasma and the molten pool on the front keyhole wall [24]. The height of liquid column would continue to elongate with the input of heat and reached $13.48 \mathrm{~mm}$ at $\mathrm{t}_{0}+$ $11.6 \mathrm{~ms}$, and formed an ellipsoid at the end. Spatters were generated when the upward momentum of ellipsoid overcame gravity and surface tension. While the remaining molten metal would be pulled back to the molten pool and re-form liquid column in a new direction. The change in the height of liquid column was exhibited in Fig. 3. Finally, a larger volume of molten metal ball would be formed at $t_{0}+60.8$ ms. The high liquid column would cause large spatters during solo-UHLW process, and thus leading to welding defects, such as undercut and surface collapse.

The solo-MAG welding process was investigated and the arc shape, spatter and droplet transfer were exhibited in Fig. 4. The low concentration of conductive ions was formed between the filler wire and workpiece because only a small amount of metal was melted under high speed welding. Resulting in the arc oscillated violently at the cathodic arc spot. Besides, the arc would deviate from the filling wire axis when arc-starting. The large spatters (with the cross-sectional area of $84.97 \mathrm{~mm}^{2}$ ), big-droplet transfer (the diameter of droplet can reach to $1.98 \mathrm{~mm}$ ) and multiple droplets transfer in one pulse also could be observed. Therefore, it was hard to guarantee the quality of weld formation.

Liquid column formation, arc shape and droplet transfer under UHLAHW process was observed in Fig. 5. During the welding process, the maximum height of liquid column was $5.43 \mathrm{~mm}$, the degree of compression could reach to $59.72 \%$ when compared with UHLW process. The laser-induced plasma would provide a conductive channel for arc, avoiding the drift of the cathode spot and maintaining the arc morphology relatively stable [25]. At the same time, the amount and the cross-sectional area of spatter would be reduced significantly when compared with solo-MAG welding. The forces of droplet were changed with the addition of laser radiation, and the diameter of the droplet was $1.2 \mathrm{~mm}$ with an uniform transition mode.

The mechanism of UHLAHW to suppress liquid column height and spatter volume could be analyzed from the characteristics of metal vapor/plasma, keyhole entrance and molten pool, as shown in Fig. 6a. A thinner layer was formed in the front when laser beam was directed at the solid metal. The effect of 
Marangoni convection at the front keyhole was not obvious due to the low temperature gradient. Hence, a huge shear force was formed between the metal vapor/plasma and the keyhole wall due to small keyhole entrance, which accelerated the rising of the molten metal. As a consequence, the high liquid column and large volume of spatter would be formed when laser welding, as shown in Fig. $6 \mathrm{~b}$. The laser beam would act on the arc crater during UHLAHW process. A large temperature gradient of molten metal was formed at the front of the keyhole and thus enhanced the Marangoni effect and enlarged the keyhole opening. The eruption speed of metal vapor would be significantly reduced, resulting in the suppression of the rising height of the liquid column, the reduction of splashing and the improvement of the process stability.

The weld appearance of UHLW, MAG welding and UHLAHW were shown in Fig. 7. Underfilling and spatters defects were observed at the UHLW (Fig. 7a), besides, continuous welds were hardly to form in high speed MAG welding(Fig. 7b). Fortunately, a sound weld appearance without obvious defects was formed under UHLAHW process (Fig. 7c). This indicated that the weldment quality of hybrid process were remarkably better than solo-laser or solo-MAG.

According to the above experimental exploration, it was found that UHLAHW could significantly suppress the height of the liquid column, reduce the spatter volume, improve the stability of the welding process, and ensure good weld formation. Therefore, the UHLAHW technology provides an effective welding method for thick plate.

\subsection{Effect of laser power on liquid column and weld formation}

Laser power was an vital parameter in LAHW, which determined the height of liquid column and the penetration depth of the joint. Besides, the arc morphology would be influenced by liquid column under a certain $D_{L A}$. To explore the effect of laser power on liquid column, the laser power changed from $9 \mathrm{~kW}$ to $27 \mathrm{~kW}$ were carried out, and three groups ( $9 \mathrm{~kW} \rrbracket 18 \mathrm{~kW} \llbracket 27 \mathrm{~kW})$ were selected for detailed analysis.

The height of liquid column changed significantly with laser power as could be seen Fig. 8. The height of liquid column was not obvious at $9 \mathrm{~kW}$ low power fiber laser, because the generated metal vapor/plasma was not enough to drive the molten metal upward (as shown in Fig. S1). There was a raised molten metal around the keyhole when the laser power reached $18 \mathrm{~kW}$, and the height of liquid column was $4.78 \mathrm{~mm}$. Moreover, the liquid column was inclined to the wire along the welding direction and finally reached 9.15 $\mathrm{mm}$ at $27 \mathrm{~kW}$. Because a strong metal vapor/plasma was generated under and a relatively large shear force was formed under this condition. Interestingly, the sprayed direction of liquid column was consistent with the welding direction and bent toward the filling wire to achieve compression of arc. To further explore the compression degree of arc by liquid column under different laser power, a total of 20 sets of arc characteristics (including arc length, height and area) at arc starting moments were extracted and statistically analyzed, and the measurement sizes were displayed in Fig. 9. The arc area was compressed from $115.94 \mathrm{~mm}^{2}$ to $105.86 \mathrm{~mm}^{2}$ when laser power increased form $9 \mathrm{~kW}$ to $18 \mathrm{~kW}$. Besides, 
the length and width of arc are basically equal at $27 \mathrm{~kW}$ and the shape was approximately spherical with an area of $92.86 \mathrm{~mm}^{2}$. The compression degree reached $19.56 \%$ when compared with $9 \mathrm{~kW}$, and thus the arc energy would be more concentrated. It could be seen that the height of liquid column exhibited an obvious effect on arc compression. In addition, the spatter was also affected by the height of liquid column as shown in Fig. S1. The size of spatter exhibited increasement trend with the upward of liquid column, indicating that liquid column was one of the important reasons for the spatters formation.

The weld formation would be influenced by laser power. As shown in Fig. 10a, an uniform weld appearance could be observed when the laser power below $18 \mathrm{~kW}$, and deteriorated at $27 \mathrm{~kW}$, because the intense gushing of liquid column would lead to unstable welding process. The penetration depth and weld width under different laser power were measured and presented in Fig. 10b. The penetration depth increased from $8.65 \mathrm{~mm}$ to $16.44 \mathrm{~mm}$ when laser power changed from $9 \mathrm{~kW}$ to $24 \mathrm{~kW}$, but only a little increasement when the laser power continued to increase by $3 \mathrm{~kW}$. This phenomenon could be caused by the combination of following two factors. On the one hand, there exhibited an extremely high concentration of metal vapor above the keyhole when the laser power reached $27 \mathrm{~kW}$, due to the violent evaporation of the material. The laser energy density that actually reached the bottom of the keyhole was reduced because the strong attenuation effect of metal vapor on the laser. On the other hand, the recoil pressure of the metal vapor was the main deriving force for maintaining the keyhole existence. When the recoil pressure was balanced with the surface tension of the molten metal, the keyhole would not continue to deepen and remained stable. Therefore, the penetration depth of the weld has a certain threshold under the specific spot diameter and welding process.

The above research indicated that the amount of jet metal vapor/plasma was remarkably increased with laser power, which eventually led to the violently rising of liquid column. Besides, the liquid column would significantly compress the arc and influence the spatter volume And the violent rising liquid column would deteriorate the weld appearance. In addition, the penetration depth increased with the improving of laser power. However, the maximum penetration depth was $16.84 \mathrm{~mm}$ in this study, because the laser penetration ability has a certain threshold under the specific spot diameter and welding process.

\subsection{Effect of welding speed on liquid column and weld formation}

Welding speed determined the welding heat input of the composite heat source, which would affect the height of liquid column, the stability of welding process and the joint morphology. Under the guarantee of sound weld formation, increasing the welding speed was of great significance to improving production efficiency. To explore the the effect of welding speed on the liquid column and weld formation under UHLAHW process, the welding speed varied from $0.9 \mathrm{~m} / \mathrm{min}$ to $1.5 \mathrm{~m} / \mathrm{min}$ in this work.

The liquid column changed significantly with welding speed during UHLAHW process, which was one of the most distinguished from the kilowatt-level hybrid welding. As shown in Fig. 11, the liquid column increased from $3.62 \mathrm{~mm}$ to $5.84 \mathrm{~mm}$ (raised by $61.33 \%$ ) when the welding speed changed from 0.9 
$\mathrm{m} / \mathrm{min}$ to $1.5 \mathrm{~m} / \mathrm{min}$. And the volume of spatters reached to $4.91 \mathrm{~mm}^{2}$ when the welding speed was 1.5 $\mathrm{m} / \mathrm{min}$. The change of liquid column was intimately related to the keyhole state. The large arc crater was formed under low welding speed, as presented in Fig. 12. There was a large amount of molten metal around the keyhole when the laser incident. At low welding speed, the rising molten metal would be pulled back to the molten pool under surface tension, leading to a low height of liquid column. Besides, the Marangoni effect was strong owing to the large temperature gradient at the front of keyhole wall, which could enlarge the keyhole entrance and reduce the shear force between metal vapor and keyhole wall. Hence, the rise of liquid column and formation of spatter could be inhibited. On the contrary, the high liquid column and large volume of spatter were formed at high welding speed, and thus deteriorated the welding stability.

The weld morphology also changed with the increase of welding speed, and a large amount of spatter could be observed on the weld surface at the speed of $1.5 \mathrm{~m} / \mathrm{min}$. The penetration depth and weld width also decreased with the increasing of welding speed, as presented in Fig. 13.

The above research indicated that the height of liquid column was raise with the welding speed. The excessive welding speed would produce a high liquid column and large spatter, and thus reduce the joint quality.

\subsection{Liquid column inhibition and process stabilization mechanism}

The aforementioned researches suggested that the process stabilization depend on the height of liquid column under UHLAHW process. While laser-arc interaction, fiber laser power and welding speed would significantly affect the liquid column, and further influence spatter volume, arc morphology, and ultimately determined the joint quality, which could be explained as follows.

The liquid column could be inhibited by hybrid process. Many researches pointed that the insufficient melt would cause a smaller diameter of keyhole entrance (d1) under single laser energy. The melt would be blown out from the keyhole and formed a certain height liquid column due to the strong shear force $\left(F_{f}\right)$ between melt and metal vapor/plasma $[26,27]$. However, during hybrid welding, the keyhole entrance (d2) was enlarged significantly by plasma flow force $\left(F_{\text {plasma }}\right)$, as shown in Fig. 14 . The preheating of arc could form a certain thickness of molten metal before laser beam irradiated, therefore, the strong Marangoni covection could be formed on the front wall of keyhole. The height of liquid column could be inhibited significantly under the high surface tension and low $F_{f}$. The concentration of metal vapor/plasma would be increased with the laser power enhanced, and thus the $F_{f}$ would increase obviously. As a result, the higher liquid column would be formed under ultra-high power laser. In addition, the number of spatter would also increase significantly, causing the weld formation quality to be impaired. Under UHLAHW process, the liquid column would rise more violently at high welding speed, because the reduction of welding heat input would reduce the thickness of melt layer, and the weakened Marangoni covection was hardly to suppress the melt rising. 
According to the above discussions, the liquid column was influenced by laser arc recombination process, laser power and welding speed. Through experimental research, the liquid column and spatter could be significantly inhibited under the welding condition of $\mathrm{P}=21 \mathrm{~kW}, \mathrm{v}=1.2 \mathrm{~m} / \mathrm{min}, \mathrm{I}=163 \mathrm{~A}, \Delta f=-2 \mathrm{~mm}$ and $D_{L A}=3 \mathrm{~mm}$, and a qualified joint with 15.82 penetration could be formed (as shown in Fig. 15).

\section{Conclusion}

The liquid column formation and inhibition mechanism under UHLAHW process has been analyzed in this work. The conclusions could be summarized as follows.

1. Under the action of ultra-high power laser, MAG preheating could significantly enlarge the keyhole entrance, and thus suppress the sharp rise of liquid column and produced a qualified weld formation.

2. The height of liquid column would significantly influenced by laser power under UHLAHW process. The excessive laser power would cause the liquid column to rise sharply, produce spatters and compress arc morphology, deteriorating the quality of weld formation.

3. The sharp rise of liquid column could be formed at high speed welding under UHLAHW process, because the reduction of welding heat input would reduce the thickness of melt layer. The weakened Marangoni covection was hardly to suppress the melt rising.

4. The liquid column and spatter could be significantly inhibited under the welding condition of $P=21$ $\mathrm{kW}, \mathrm{v}=1.2 \mathrm{~m} / \mathrm{min}, \mathrm{l}=163 \mathrm{~A}, \Delta f=-2 \mathrm{~mm}$ and $D_{L A}=3 \mathrm{~mm}$, and a qualified joint with $15.82 \mathrm{~mm}$ penetration could be formed.

\section{Declarations}

\section{CRediT authorship contribution statement}

Yan Li: Writing - original draft, Writing - review \& editing, Conceptualization, Investigation, Formal analysis, Methodology, Validation, Data curation. Shaoning Geng: Resources,Writing - review \& editing, Methodology. Siyuan Gu: Investigation. Dehua Huang: Investigation. Yilin Wang: Investigation, Validation, Formal analysis. Gaoyang Mi: Resources,Writing - review \& editing, Methodology. Ping Jiang: Supervision, Resources, Writing - review \& editing.

\section{Acknowledgements}

This research has been supported by the National Natural Science Foundation of China under Grant No.52075201, No.51861165202, the Postdoctoral Science Foundation of China under Grant No.2020M682407, the Fundamental Research Funds for the Central Universities (HUST), HUST:2020JYCXJJ038. We would like to express our deep gratitude to the Analysis and Test Center of HUST (Huazhong University of Science and Technology) and the State Key Laboratory of Material Processing and Die \& Mold Technology of HUST, for their friendly cooperation. 


\section{Data availability}

All data generated in this research are included in the manuscript.

\section{Code availability}

The code in this manuscript can be shared.

Ethics approval: Not applicable.

Consent to participate: All authors have supported participation.

Consent for publication: The manuscript was approved by all authors for publication.

Conflict of interest: The authors declare that they have no known competing financial interests or personal relationships that could have appeared to influence the work reported in this paper.

\section{References}

1. Nielsen SE (2015) High Power Laser Hybrid Welding - Challenges and Perspectives. Physics Procedia 78:24-34

2. Huang H, Zhang P, Yan H, Liu Z, Yu Z, Wu D, Shi H, Tian Y (2021) Research on weld formation mechanism of laser-MIG arc hybrid welding with butt gap. Opt Laser Technol 133:106530

3. Bunaziv I, Frostevarg J, Ren X, Kaplan AF, H.,Akselsen OM (2019) Porosity and solidification cracking in welded $45 \mathrm{~mm}$ thick steel by fiber laser-MAG process. Procedia Manuf 36:101-111

4. Zhang MJ, Chen GY, Zhou Y, Li SC, Deng H (2013) Observation of spatter formation mechanisms in high-power fiber laser welding of thick plate. Appl Surf Sci 280:868-875

5. Kawahito Y, Wang H, Katayama S, Sumimori D (2018) Ultra high power (100 kW) fiber laser welding of steel. Opt Lett 43(19):4667-4670

6. Wang J, Peng G, Li L, Si C, Meng S, Gong J (2019) 30 kW-level laser welding characteristics of 5A06 aluminum alloy thick plate under subatmospheric pressure. Opt Laser Technol 119:105668

7. Wu D, Hua X, Huang L, Zhao J (2018) Numerical simulation of spatter formation during fiber laser welding of 5083 aluminum alloy at full penetration condition. Opt Laser Technol 100:157-164

8. Fabbro R (2010) Melt pool and keyhole behaviour analysis for deep penetration laser welding. J Phys D 43(44):445501

9. Wu D, Hua X, Li F, Huang L (2017) Understanding of spatter formation in fiber laser welding of 5083 aluminum alloy. Int $\mathrm{J}$ Heat Mass Transf 113:730-740

10. Xu J, Luo Y, Zhu L, Han J, Zhang C, Chen D (2019) Effect of shielding gas on the plasma plume in pulsed laser welding. Measurement 134:25-32

11. Wu D, Hua X, Huang L, Li F, Cai Y (2019) Observation of the keyhole behavior, spatter, and keyholeinduced bubble formation in laser welding of a steel/glass sandwich. Weld World 63(3):815-823 
12. Wang Y, Jiang P, Zhao J, Geng S (2021) xu B. Effects of energy density attenuation on the stability of keyhole and molten pool during deep penetration laser welding process: A combined numerical and experimental study. International Journal of Heat and Mass Transfer 176: 121410

13. Sun J, Wu CS, Feng Y (2011) Modeling the transient heat transfer for the controlled pulse key-holing process in plasma arc welding. Int J Therm Sci 50(9):1664-1671

14. Li L, Peng G, Wang J, Gong J, Meng S (2019) Numerical and experimental study on keyhole and melt flow dynamics during laser welding of aluminium alloys under subatmospheric pressures. Int $\mathrm{J}$ Heat Mass Transf 133:812-826

15. Ai Y, Jiang P, Wang C, Mi G, Geng S (2018) Experimental and numerical analysis of molten pool and keyhole profile during high-power deep-penetration laser welding. Int J Heat Mass Transf 126:779789

16. Schmidt L, Schricker K, Bergmann JP, Junger C (2020) Effect of Local Gas Flow in Full Penetration Laser Beam Welding with High Welding Speeds.Applied Sciences10 (5)

17. Liu XF, Jia CB, Wu CS, Zhang GK, Gao JQ (2017) Measurement of the keyhole entrance and topside weld pool geometries in keyhole plasma arc welding with dual CCD cameras. J Mater Process Technol 248:39-48

18. Kim J, Oh S, Son M, Ki H (2017) A study of keyhole behavior and weldability in zero-gap laser welding of zinc-coated steel sheets at subatmospheric pressures. J Mater Process Technol 249:135148

19. Wang L, Gao X, Chen Z (2018) Status analysis of keyhole bottom in laser-MAG hybrid welding process. Opt Express 26(1):347-355

20. Wu D, Van Nguyen A, Tashiro S, Hua X, Tanaka M (2019) Elucidation of the weld pool convection and keyhole formation mechanism in the keyhole plasma arc welding. Int J Heat Mass Transf 131:920931

21. Wang L, Gao X, Chen Z (2018) Status analysis of keyhole bottom in laser-MAG hybrid welding process. Opt Express 26(1):347-355

22. Bunaziv I, Dørum C, Nielsen SE, Suikkanen P, Ren X, Nyhus B, Eriksson M, Akselsen OM (2020) Laserarc hybrid welding of 12- and 15-mm thick structural steel. Int J Adv Manuf Technol 107(5):26492669

23. Liu W, Ma J, Yang G, Kovacevic R (2014) Hybrid laser-arc welding of advanced high-strength steel. J Mater Process Technol 214(12):2823-2833

24. Hiroshi N, Yousuke K, Seiji K (2015) Fundamental Study for the Relationship between Melt Flow and Spatter in High-Power Laser Welding of Pure Titanium. Trans Jwri 44(2):27-32

25. Liu S, Chen S, Wang Q, Li Y, Zhang H, Ding H (2017) Analysis of plasma characteristics and conductive mechanism of laser assisted pulsed arc welding. Opt Lasers Eng 92:39-47

26. Katayama S, Gapontsev DV, Kawahito Y, Kliner DA, Dawson JW, Tankala K (2009) Elucidation of phenomena in high-power fiber laser welding and development of prevention procedures of welding defects. 7195:71951R 
27. Qinglong PaMM, Kawahito Y, Katayama S (2016) High power disk laser-metal active gas arc hybrid welding of thick high tensile strength steel plates. JOURNAL OF LASER APPLICATIONS VOLUME 28, NUMBER 1

\section{Figures}

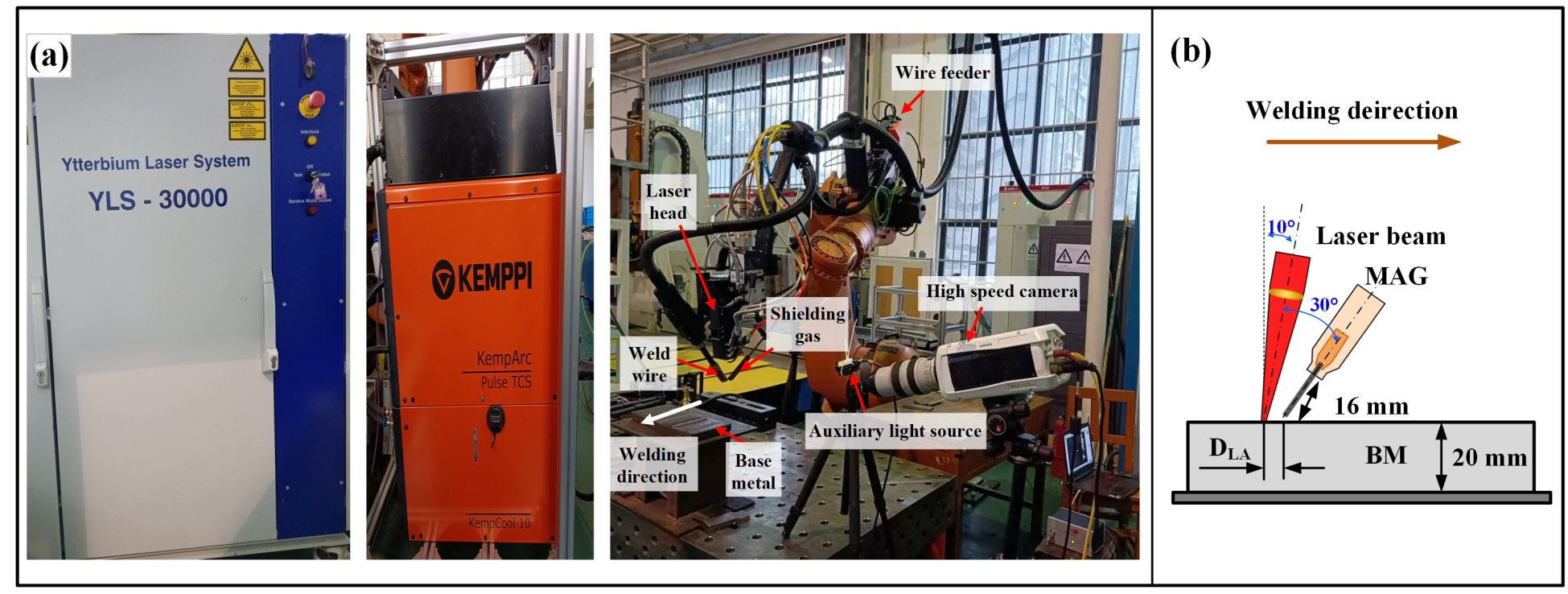

Figure 1

Schematic of (a) experimental setup and (b) welding processes.

Figure 2

Liquid column and spatters formation during solo-UHLW process (parameters: $\mathrm{P}=21 \mathrm{~kW}, \mathrm{v}=1.2 \mathrm{~m} / \mathrm{mim}, \Delta t$ $=-2 \mathrm{~mm})$.

\section{Figure 3}

Variation of liquid column and spatter cross-sectional area during solo-UHLW process (parameters: $\mathrm{P}=21$ $\mathrm{kW}, \mathrm{v}=1.2 \mathrm{~m} / \mathrm{mim}, \Delta f=-2 \mathrm{~mm}$ ). 


\section{Figure 4}

Arc shape, spatter and droplet transfer during solo-MAG welding (parameters: I=163 A, v=1.2 m/min).

\section{Figure 5}

Liquid column formation, arc shape and droplet transfer under UHLAHW (parameters: $\mathrm{P}=21 \mathrm{~kW}, \mathrm{l}=163 \mathrm{~A}$, $\left.\mathrm{v}=1.2 \mathrm{~m} / \mathrm{min}, \Delta f=-2 \mathrm{~mm}, D_{L A}=3 \mathrm{~mm}\right)$.

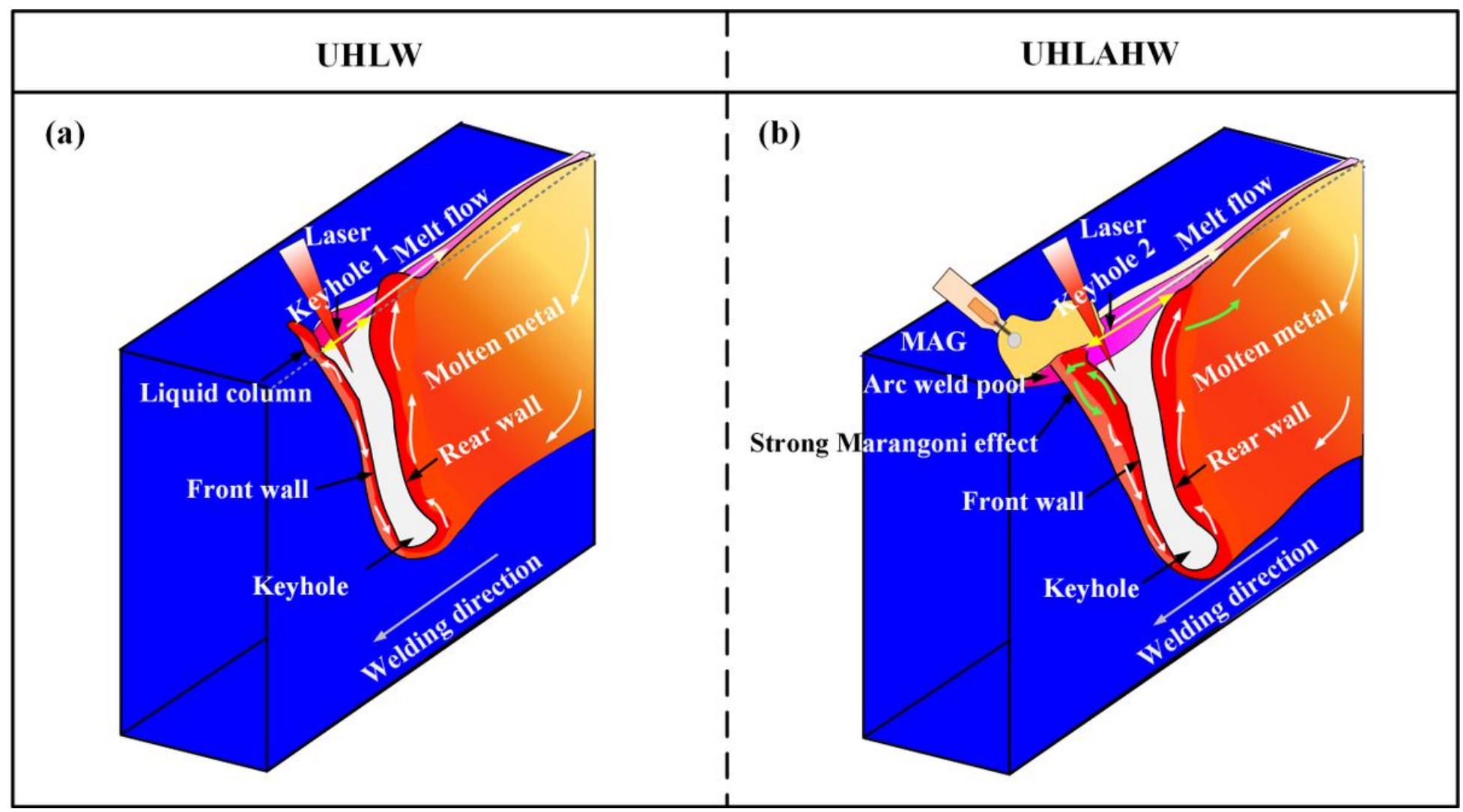

\section{Figure 6}

Schematic of molten pool flow under (a) solo-UHLW and (b) UHLAHW, (c) schematic of the force analysis on the keyhole wall under solo-UHLW and (d) UHLAHW. 


\section{Figure 7}

Welding formation under different condition, (a) solo-UHLW, (b) solo-MAG welding, (c) UHLAHW (parameters: $\mathrm{P}=21 \mathrm{~kW}, \mathrm{l}=163 \mathrm{~A}, \mathrm{v}=1.2 \mathrm{~m} / \mathrm{min}, \Delta f=-2 \mathrm{~mm}, D_{L A}=3 \mathrm{~mm}$ ).

\section{Figure 8}

Effect of the laser power on liquid column (parameters: I=163 A, v=1.2 m/min, $\Delta f=-2 \mathrm{~mm}, D_{L A}=3 \mathrm{~mm}$ ).

\section{Figure 9}

Arc characteristic size under different laser power (parameters: I=163 A, v=1.2 m/min, $\Delta f=-2 \mathrm{~mm}, D_{L A}=3$ $\mathrm{mm})$.

\section{Figure 10}

Effect of the laser power on weld formation (a), and penetration depth and weld width (b) (parameters: $\mathrm{l}=163 \mathrm{~A}, \mathrm{v}=1.2 \mathrm{~m} / \mathrm{min}, \Delta f=-2 \mathrm{~mm}, D_{L A}=3 \mathrm{~mm}$ ).

\section{Figure 11}

(a) Liquid column and (b) spatter formation under different welding speed (parameters: $\mathrm{P}=21 \mathrm{~kW}, \mathrm{l}=163$ A, $\Delta f=-2 \mathrm{~mm}, D_{L A}=3 \mathrm{~mm}$ ). 
Figure 12

Effect of the welding speed on large keyhole and liquid column.

Figure 13

Effect of the welding speed on weld formation (parameters: $\mathrm{P}=21 \mathrm{~kW}, \mathrm{l}=163 \mathrm{~A}, \Delta f=-2 \mathrm{~mm}, D_{L A}=3 \mathrm{~mm}$ ).

Figure 14

Liquid column inhibition mechanism.

\section{Figure 15}

Liquid column, spatter and weld formation under optimal welding condition (parameters: $\mathrm{P}=21 \mathrm{~kW}, \mathrm{v}=1.2$ $\left.\mathrm{m} / \mathrm{min}, \mathrm{l}=163 \mathrm{~A}, \Delta f=-2 \mathrm{~mm}, D_{L A}=3 \mathrm{~mm}\right)$.

\section{Supplementary Files}

This is a list of supplementary files associated with this preprint. Click to download.

- SupplementaryMaterial.doc 